\title{
Drug-loading capacity and nuclear targeting of multiwalled carbon nanotubes grafted with anionic amphiphilic copolymers
}

This article was published in the following Dove Press journal:

International Journal of Nanomedicine

18 November 2013

Number of times this article has been viewed

\author{
Hsieh-Chih Tsai ${ }^{1, *}$ \\ Jeng-Yee Lin 2,* \\ Faiza Maryani' \\ Chun-Chiang Huang' \\ Toyoko Imae ${ }^{1,3}$
}

'Graduate Institute of Applied Science and Technology, ${ }^{2}$ Division of Plastic Surgery, Department of Surgery, Taipei Medical University Hospital, Taipei Medical University, ${ }^{3}$ Department of Chemical Engineering, National Taiwan University of Science and Technology,

Taipei, Taiwan

*These authors contributed equally to this work
Correspondence: Hsieh-Chih Tsai Graduate Institute of Applied Science and Technology, National

Taiwan University of Science and

Technology, 43 Section 4 Keelung Road,

Da'an District, Taipei 106, Taiwan

Tel +8862 27303779

Fax +886227303733

Email h.c.tsai@mail.ntust.edu.tw
Abstract: In this study, three types of hybrid nanotubes (NTs), ie, oxidized multiwalled carbon NTs (COOH MWCNTs), heparin (Hep)-conjugated MWCNTs (Hep MWCNTs), and diblock copolymer polyglycolic acid (PGA)-co-heparin conjugated to MWCNTs (PGA MWCNTs), were synthesized with improved biocompatibility and drug-loading capacity. Hydrophilic Hep substituents on MWCNTs improved biocompatibility and acted as nucleus-sensitive segments on the CNT carrier, whereas the addition of PGA enhanced drug-loading capacity. In the PGA MWCNT system, the amphiphilic copolymer (PGA-Hep) formed micelles on the side walls of CNTs, as confirmed by electron microscopy. The PGA system encapsulated the hydrophobic drug with high efficiency compared to the COOH MWCNT and Hep MWCNT systems. This is because the drug was loaded onto the PGA MWCNTs through hydrophobic forces and onto the CNTs by $\pi-\pi$ stacking interactions. Additionally, most of the current drug-carrier designs that target cancer cells release the drug in the lysosome or cytoplasm. However, nuclear-targeted drug release is expected to kill cancer cells more directly and efficiently. In our study, PGA MWCNT carriers effectively delivered the active anticancer drug doxorubicin into targeted nuclei. This study may provide an effective strategy for the development of carbon-based drug carriers for nuclear-targeted drug delivery.

Keywords: carbon nanotube, amphiphilic copolymer, drug loading, nucleus targeting, cancer therapy

\section{Introduction}

Recently, research and applications in the field of nanoscience and nanotechnology have seen unprecedented growth. There is increasing optimism that the use of nanotechnology in medical applications will lead to significant progress in the diagnosis and treatment of disease. ${ }^{1}$ To utilize successfully the new generation of nanomaterials as drug carriers for disease treatment, it is essential to determine their pharmacological and toxicological profiles. Carbon nanotubes (CNTs) are nanoparticles that have demonstrated great potential for biomedical applications, such as in drug delivery; however, biosafety remains an important concern. ${ }^{2,3}$ CNTs interact with mammalian cells and enter them via cytoplasmic translocation, and thus they can deliver a range of therapeutic reagents into the cell. ${ }^{4}$ The unique ability of CNTs to penetrate cell membranes enables them to deliver therapeutic agents into the cytoplasm and in many cases the nucleus of the cell. ${ }^{5,6}$

Different strategies have been developed that load drug molecules onto CNTs through either covalent bonds or noncovalent adsorption. ${ }^{7-10}$ However, covalent bonds between the CNT and carrier are inadequate, because a slight change in the 
molecular structure of a drug may drastically change its specificity. Therefore, most drugs are loaded onto CNT carriers through physical adsorption. CNTs have an aromatic ring surface, which allows hydrophobic interactions (including $\pi-\pi$ stacking) to occur between the drug and the CNT. ${ }^{10}$ However, the loading capacity of CNTs is limited, and drugs loaded on the exterior of the carrier are directly exposed. One solution is to incorporate hydrophilic polymers on the side walls of CNTs, which improves CNT biocompatibility but only slightly increases drug-loading capacity. ${ }^{11}$ Therefore, drug-loading efficiency remains a critical component in drug-carrier design. We aim to design CNTs conjugated with amphiphilic copolymers that form polymeric micelles on the side walls of CNTs and provide three-dimensional space to encapsulate a large amount of drugs in the carrier.

Many anticancer drugs, such as anthracylines, camptothecin, cisplatin, and doxorubicin (Dox), are deoxyribonucleic acid (DNA) toxins that target nuclear DNA. These drugs cause oxidative DNA damage and cell death (apoptosis) by generating free radicals and inhibiting topoisomerase II. ${ }^{12,13}$ Therefore, they must be transported directly into the nucleus to initiate a pharmacological response. ${ }^{14}$ However, because cytoplasmic delivery of anticancer drugs is inadequate, ${ }^{15}$ nuclear delivery mechanisms should be utilized. Pantarotto et al reported the nuclear accumulation of CNTs ${ }^{16}$ and the ability of peptide-conjugated multiwalled CNTs (MWCNTs) to penetrate the nuclear membrane, which may be effectively applied to the delivery of plasmid DNA. ${ }^{17}$ Many studies have focused on the uptake of CNTs, ${ }^{18}$ but to our knowledge there have been no reports on CNT-based drug delivery to the nucleus.

Amphiphilic diblock polyglycolic acid (PGA)-co-heparin (Hep)-conjugated MWCNTs were synthesized in this study. Why was Hep selected to be conjugated to nuclear-targeting CNT carriers? This is because Hep acts as a nucleus-sensitive molecule on the CNT carrier. It has been reported that Hep can interact with proteins in the nucleus ${ }^{19,20}$ and release loaded drugs from PGA MWCNTs. In addition, the hydrophilic segments of Hep are located on the exterior, which promotes the dispersion of MWCNTs in water. ${ }^{21}$ In the PGA MWCNT system, Dox was loaded onto CNTs through $\pi-\pi$ stacking and hydrophobic interactions between the PGA and CNTs. This capability makes PGA MWCNTs a good candidate for a nuclear-targeting drug carrier. When we evaluated the drug release behavior of PGA MWCNTs in simulated lysosomal and cytoplasmic environments, the amphiphilic diblock PGA-co-Hep protected the drug in the carrier so that only a small amount of drug was released. In addition, we found that PGA MWCNTs directly targeted and released the drug in the nucleus of HeLa cells, as observed by confocal microscopy. The PGA MWCNT carrier not only demonstrated improved drug-loading capability but also nuclear-targeting ability for the delivery of DNA toxins.

\section{Materials and methods}

All chemicals used were of analytical grade and are available from commercial sources. MWCNTs, 1-(3-dimethylaminopropyl)-3-ethylcarbodiimide hydrochloride $98+\%$ (EDC), and $N$-hydroxysuccinimide $98+\%$ (NHS) were obtained from Acros Organics (Thermo Fisher Scientific, Waltham, MA, USA), nitric acid $\left(\mathrm{HNO}_{3}\right)$ was obtained from Merck KGaA (Darmstadt, Germany), and Hep sodium salt from porcine intestinal mucosa and PGA was obtained from Sigma-Aldrich (St Louis, MO, USA).

\section{Synthesis of oxidized MWCNTs}

To prepare an aqueous solution of oxidized $(\mathrm{COOH}) \mathrm{CNTs}$, MWCNTs $(50 \mathrm{mg})$ were refluxed in $\mathrm{HNO}_{3}(50 \mathrm{~mL})$ at $100^{\circ} \mathrm{C}$ for 24 hours. After cooling at room temperature, the CNTs were vacuum-filtered and washed with deionized water until the filtrate reached a neutral $\mathrm{pH}$. The oxidized MWCNTs were dried in a vacuum oven at $50^{\circ} \mathrm{C}$ overnight.

\section{Synthesis of heparin- conjugated MWCNTs}

$\mathrm{COOH} \mathrm{CNTs}(2 \mathrm{mg} / \mathrm{mL})$ were suspended in water in the presence of EDC $(2 \mathrm{mg} / \mathrm{mL})$ and NHS $(0.5 \mathrm{mg} / \mathrm{mL})$. The reaction mixture was kept at $\mathrm{pH} 7.0$ and reacted for 24 hours. Commercial Hep with a molecular weight of approximately 17,000-19,000 Da (2 mg/mL) was then added to the solution, and the mixture was stirred for 24 hours. To obtain Hep MWCNTs, excess free Hep was removed via dialysis (tube with molecular weight of 25,000 Da) against fresh water for 1 day.

\section{Synthesis of polyglycolic acid-conjugated heparin MWCNTs}

To synthesize PGA MWCNTs, $2 \mathrm{mg} / \mathrm{mL}$ of PGA (molecular weight of 15,000 Da) was dissolved in dimethyl sulfoxide (DMSO) in the presence of EDC ( $2 \mathrm{mg} / \mathrm{mL})$ and NHS $(0.5 \mathrm{mg} / \mathrm{mL})$. Then, a similar synthesis procedure was followed for the reaction and purification of Hep MWCNTs.

\section{Probing the hydrophobic interactions between pyrene and CNT carriers}

Solutions of $\mathrm{COOH}$, Hep, and PGA MWCNTs were prepared at the following concentrations: $3.2,1.6,0.8,0.4$, 
0.2 , and $0.1 \mathrm{mg} / \mathrm{mL}$. Pyrene was dissolved in acetone, and equal amounts of pyrene solution were added to each MWCNT solution and stirred for 24 hours. The acetone was removed using a rotary evaporator, and the pyrene concentration remained stable at $1.2 \times 10^{-6} \mathrm{M}$ after 24 hours in water. Pyrene-loaded $\mathrm{COOH}$, Hep, and PGA MWCNTs were characterized by fluorescence spectroscopy, and the measured fluorescence-intensity ratio was used to determine the association between the hydrophobic labels.

\section{Drug loading of CNT carriers}

Dox (1 mg) was dissolved in $3 \mathrm{~mL}$ of DMSO, then triethylamine was added to the Dox solution and stirred for 30 minutes. After stirring, $0.33 \mathrm{mg} / \mathrm{mL}$ Dox was added to $0.162 \mathrm{mg} /$ $\mathrm{mL}$ solutions of each sample (ie, $\mathrm{COOH}, \mathrm{Hep}$, and PGA
MWCNTs). Excess drugs were removed by dialysis with a molecular weight cutoff of 1,000 Da. Then, the drug-loading efficiency of the samples was determined by ultraviolet measurements.

\section{Synthesis of fluorescein isothiocyanate- labeled PGA MWCNTs}

To synthesize fluorescein isothiocyanate (FITC)-labeled PGA MWCNTs, $1 \mathrm{mg}$ PGA MWCNTs reacted with hexamethylene diamine $\left(\mathrm{NH}_{2}\left[\mathrm{CH}_{2}\right]_{6} \mathrm{NH}_{2}\right)$ in the presence of $1 \mathrm{mg}$ EDC and $0.05 \mathrm{mg}$ NHS to create a linkage between PGA MWCNTs and the fluorescein molecule. To ensure the FITC could be dissolved well in water, the solution was controlled at $\mathrm{pH}$ 9.0. Excess FITC was removed by water dialysis for 24 hours using a molecular weight cutoff 1,000 Da membrane. Quantitative analysis of the amount of conjugated
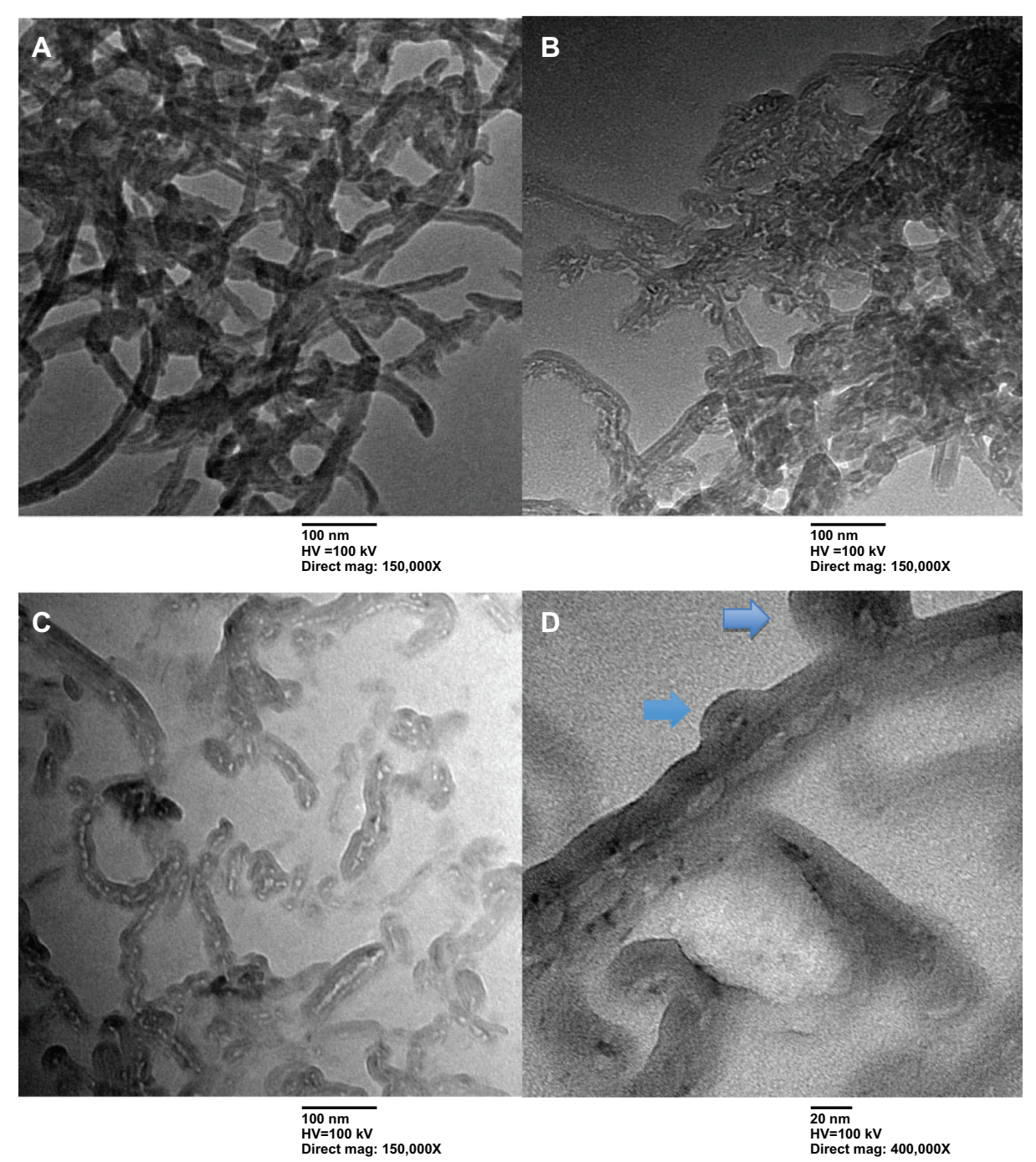

Figure I Transmission electron microscopy images of multiwalled (A) oxidized, (B) heparin, and (C) polyglycolic acid (PGA) carbon nanotubes at low magnification (mag), and (D) multiwalled PGA carbon nanotubes at high magnification. The arrows in (D) denote the formation of polymeric micelles on the multiwalled carbon nanotubes (MWCNTs). 
FITC was determined by measuring the fluorescence intensity (Supplementary materials).

\section{Carrier biocompatibility}

The cytotoxic effects of $\mathrm{COOH}$, Hep and PGA MWCNTs were characterized by an MTT (3-[4,5-dimethylthiazol2-yl]-2,5 diphenyltetrazolium bromide) assay. HeLa cells were seeded at a density of $5 \times 10^{3}$ cells/well and cultured for 1 day. HeLa cells were cultured in 96-well plates with Dulbecco's Modified Eagle's Medium (DMEM) containing 10\% fetal bovine serum (FBS). After washing twice with phosphatebuffered saline (PBS), cells were incubated with the carriers for an additional 24 hours. The results are expressed as the percentage of viable cells compared to the control group.

\section{Internalization}

Dox-loaded PGA MWCNTs that were internalized by HeLa cells were visualized using an LTCS SP5 confocal spectral microscopy imaging system (Leica Microsystems, Wetzlar, Germany). HeLa cells were cultured on cover slides for 24 hours and treated with either free Dox or Dox-loaded PGA MWCNTs. The concentration of Dox was fixed at $1 \mu \mathrm{g} / \mathrm{mL}$. After 2 hours of incubation, cells were washed with PBS and mounted on a slide with $4 \% \mathrm{w} / \mathrm{w}$ paraformaldehyde for confocal observation. Fluorescence was observed by confocal microscopy using $488 \mathrm{~nm}$ excitation and a long-pass filter of either $590 \mathrm{~nm}$ for Dox detection or $520 \mathrm{~nm}$ for FITC detection.

\section{Nuclear-targeting efficiency}

In order to compare the nuclear-targeting efficiency of Dox and Dox-loaded PGA MWCNTs, growth activity and inhibition was evaluated with MTT assays. HeLa cells were cultured in 96-well plates with DMEM containing $10 \%$ FBS. Cells were seeded at a density of $5 \times 10^{3}$ cells/ well and cultured for 1 day. After washing twice with PBS, cells were incubated with free drugs or Dox-loaded PGA MWCNTs for an additional 24 hours. The results are expressed as the percentage of viable cells compared to the control group.

\section{Measurements}

To characterize the CNT grafting polymers, $\mathrm{COOH}$, Hep, and PGA MWCNTs were monitored via Fourier-transform infrared (FTIR) spectroscopy (Nicolet 6700; Thermo Fisher Scientific). For FTIR measurements, sample solutions were pipetted onto a $\mathrm{CaF}_{2}$ pellet and dried in a vacuum oven. Sample morphology and particle size were visualized with field-emission scanning electron microscopy (FE-SEM;
JSM-6500F; JEOL, Tokyo, Japan) and transmission electron microscopy (TEM) (H-7000; Hitachi, Tokyo, Japan). Raman spectra were recorded on a Raman spectroscope (Jobin Yvon
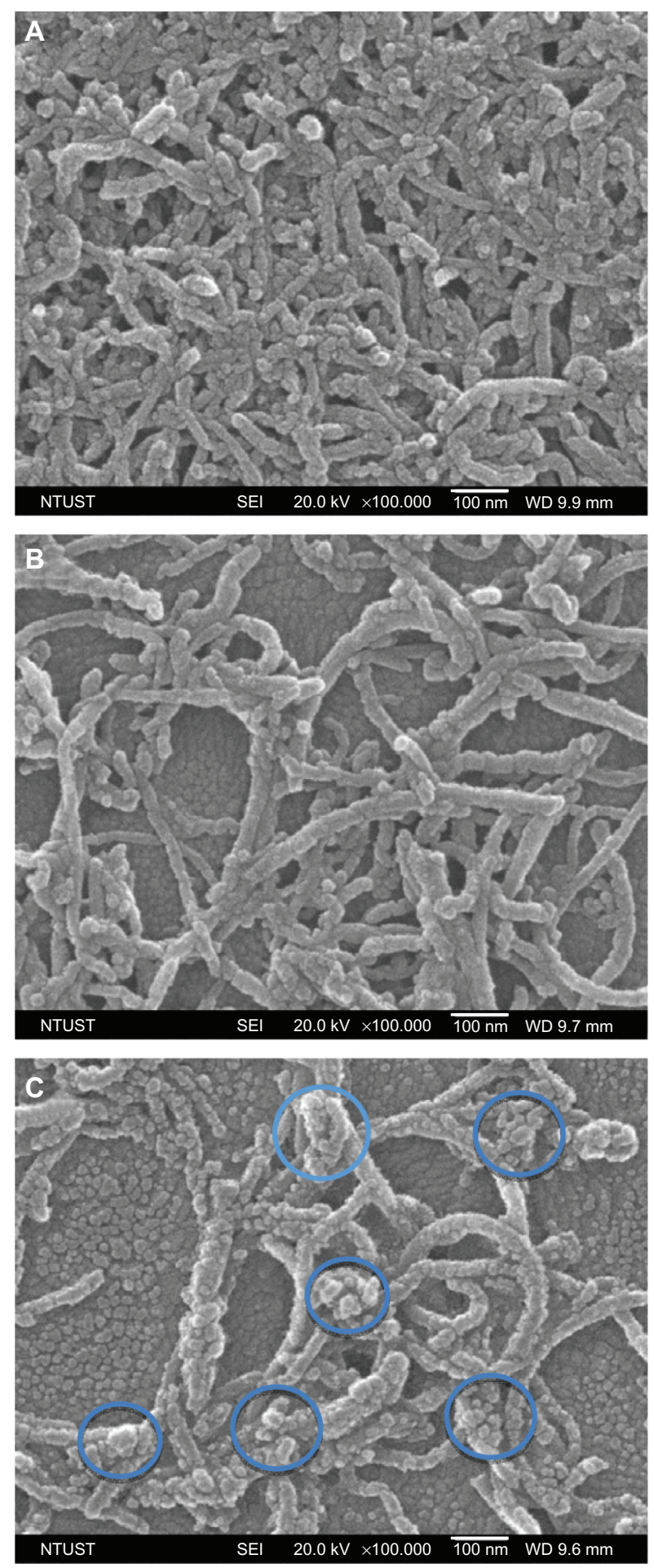

Figure 2 Scanning electron microscopy images of multiwalled (A) oxidized, (B) heparin, and (C) polyglycolic acid carbon nanotubes. The blue circles in (D) denote the formation of polymeric micelles on multiwalled carbon nanotubes (MWCNTs). Abbreviations: NTUST, National Taiwan University of Science and Technology; SEl, second electron imaging; WD, working distance. 
iHR550; Horiba, Kyoto, Japan) with an excitation wavelength of $684 \mathrm{~nm}$. The hydrodynamic size, polydispersity index (PDI), and zeta potential of sample suspensions were analyzed using an SZ-100 nanoparticle analyzer (Horiba). The fluorescence spectra were recorded using a fluorescence spectrophotometer (F-7000; Hitachi). Drug-loading efficiency, which was based on the absorbance of Dox, was characterized using an ultraviolet spectrophotometer (V670; Jasco, Tokyo, Japan).

\section{Results and discussion FTIR spectroscopy results}

In this study, three types of CNT carriers were synthesized, purified, and evaluated in terms of drug-loading efficiency. Infrared spectral data were used to study the chemical linkage between Hep and oxidized MWCNTs (Hep MWCNTs). We discovered a new ester bond in Hep MWCNTs, ie, an ester $\mathrm{C}=\mathrm{O}$ stretch at $1,750-1,735 \mathrm{~cm}^{-1}$. Although unlikely, ester bonds can also form between carboxyl groups of COOH MWCNTs and hydroxyl groups of Hep. ${ }^{22}$ The peaks at 1,710 and $3,450 \mathrm{~cm}^{-1}$ are attributed to acidic groups, such as carboxyl, phenol, and lactol groups, whereas the peak at $1,576 \mathrm{~cm}^{-1}$ is attributed to the $\mathrm{C}=\mathrm{C}$ bond of the
CNTs. The spectra are shown in Figure S1A. By contrast, because of the presence of overlapping bonds, the FTIR spectra in Figure S1B do not clearly indicate the formation of PGA MWCNTs. Therefore, the characterization of PGA MWCNTs was completed using TEM, SEM, and Raman scattering spectroscopy analyses.

\section{Transmission and scanning electron microscopy results}

TEM was used to examine the morphology of the amphiphilic copolymers grafted to the CNTs. As expected, a thin polymer layer was observed for Hep MWCNTs (Figure 1B) and PGA MWCNTs (Figure 1C), but not $\mathrm{COOH}$ MWCNTs (Figure 1C). CNTs fragmented into smaller pieces after chemical conjugation with the amphiphilic copolymer. Notably, spherical particles formed on the side walls of the CNTs, as shown in Figure 1D.

The morphology and microstructure of $\mathrm{COOH}$, Hep, and PGA MWCNTs were further investigated using SEM, as shown in Figure 2. A larger diameter was measured for PGA MWCNTs (average diameter $37 \mathrm{~nm}$ ) than $\mathrm{COOH}$ MWCNTs (average diameter $28 \mathrm{~nm}$ ) and Hep MWCNTs (average diameter $35 \mathrm{~nm}$ ), which is shown in

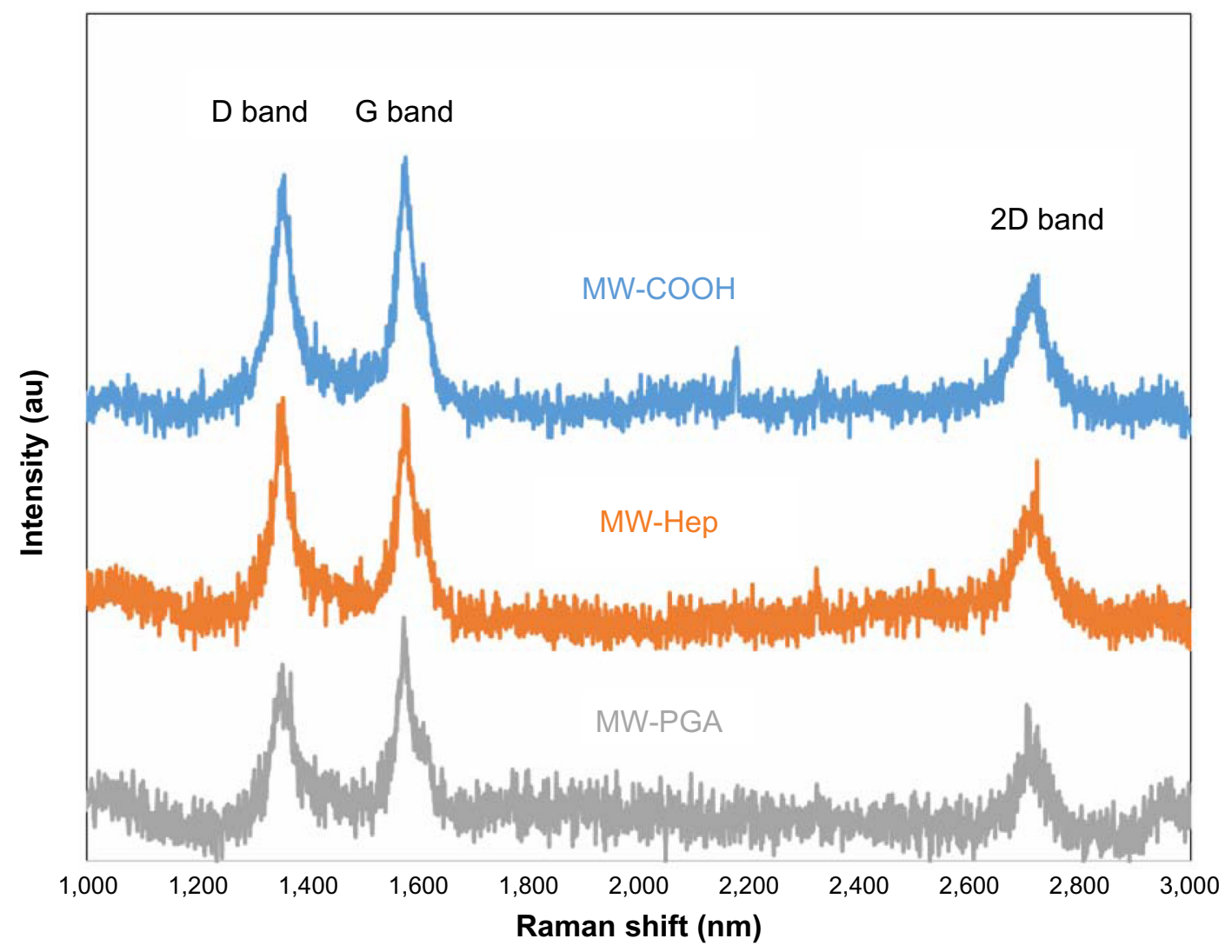

Figure 3 Raman spectra of multiwalled (MW) oxidized (COOH), MW heparin (Hep), and MW polyglycolic acid (PGA) carbon nanotubes. 
Figure 2A and B. In addition, we found spherical particles on the side walls of MWCNTs in the PGA system, as shown in Figure 2C. In the PGA MWCNT system, the hydrophobic part consisted of the PGA and CNTs, whereas the hydrophilic part consisted of Hep, which was located in between the PGA and the CNT. Because PGA MWCNTs were dispersed in an aqueous solution, the hydrophobic interactions between the PGA and CNTs created an amphiphilic copolymer that formed micelles on the side walls of the CNTs.

\section{Raman spectroscopy results}

Raman scattering spectroscopy has been extensively utilized to study the vibration of CNTs. In particular, vibration spectra can provide useful insights toward the functionalization states of CNTs. Two peaks were observed in the Raman spectra

A

Size distribution by intensity

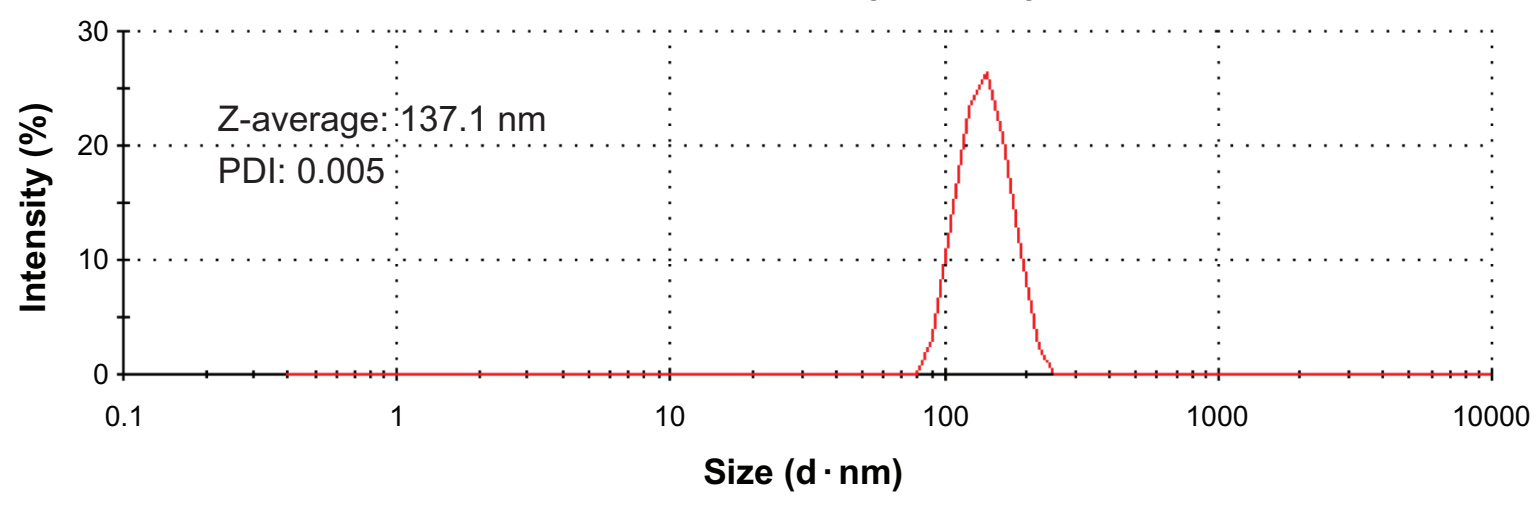

B Size distribution by intensity

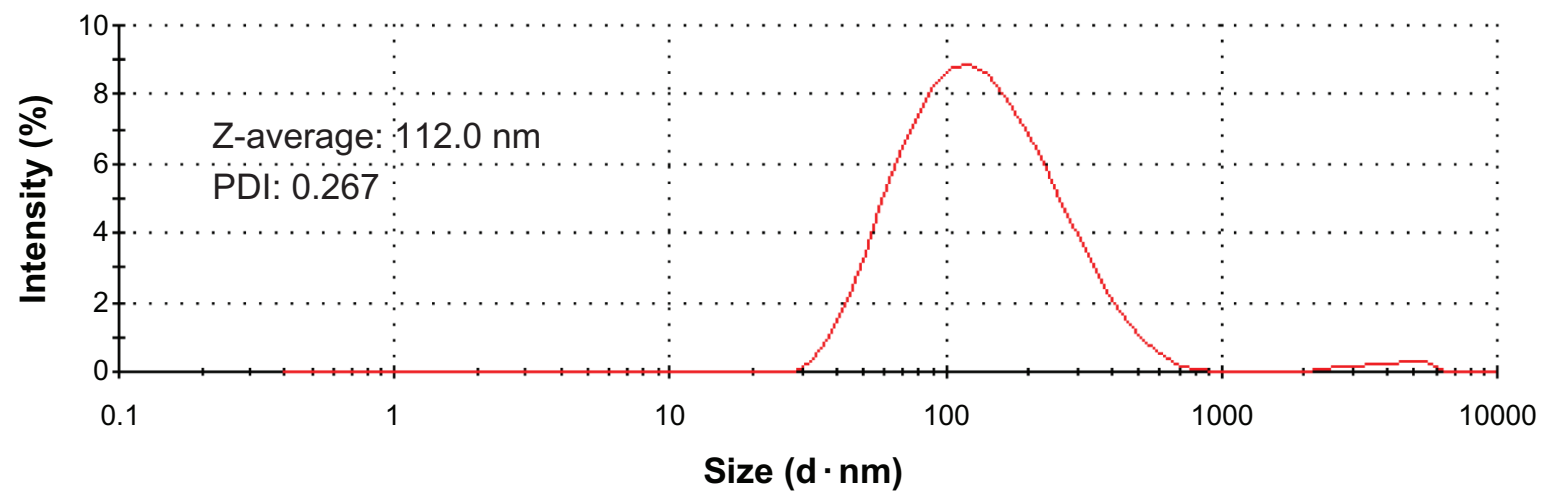

C Size distribution by intensity

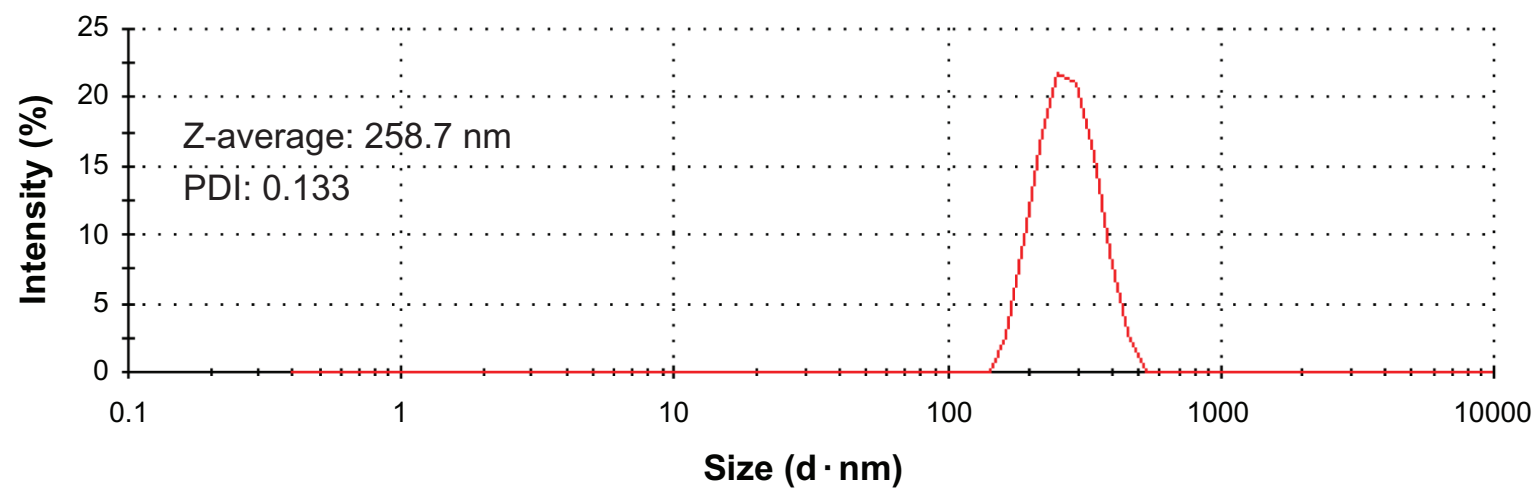

Figure 4 Particle size and distribution of multiwalled (A) oxidized, (B) heparin, and (C) polyglycolic acid carbon nanotubes analyzed by dynamic light scattering. Abbreviation: PDI, polydispersity index; Z-average, hydrodynamic diameter. 
of the CNTs (Figure 3): the D band (defective structure) at $1,355 \mathrm{~cm}^{-1}$ and the $\mathrm{G}$ band (graphite structure) at $1,575 \mathrm{~cm}^{-1}$. Therefore, the intensity ratio, $\mathrm{I}_{\mathrm{D}} / \mathrm{I}_{\mathrm{G}}$, strongly depends on the fraction of defective CNTs. The ratio $\mathrm{I}_{\mathrm{D}} / \mathrm{I}_{\mathrm{G}}$ was calculated as follows:

$$
\begin{gathered}
\mathrm{I}_{\mathrm{D}} / \mathrm{I}_{\mathrm{G}}(\mathrm{COOH} \text { MWCNTs })=247.42 / 262.11=0.94 \\
\mathrm{I}_{\mathrm{D}} / \mathrm{I}_{\mathrm{G}}(\text { Hep MWCNTs })=185.6 / 193.2=0.96 \\
\mathrm{I}_{\mathrm{D}} / \mathrm{I}_{\mathrm{G}}(\text { PGA MWCNTs })=112.2 / 130.6=0.85
\end{gathered}
$$

The different ratios confirm that the defect sites were affected by the incorporation of Hep and block copolymer (Hep-co-PGA). We discovered that $\mathrm{COOH}$ and Hep MWCNTs had similar ratios $\left(\mathrm{I}_{\mathrm{D}} / \mathrm{I}_{\mathrm{G}}\right)$. In fact, even though a chemical reaction was required to incorporate Hep on the MWCNTs, which might slightly damage the graphite structure, an increase in the number of CNT defects $(\mathrm{COOH}$ MWCNTs) was not observed. However, when PGA was introduced onto Hep MWCNTs, the amphiphilic copolymer (ie, poly[Hep-co-PGA]) seemed to recover the defects and disorder that were observed for $\mathrm{COOH}$ MWCNTs. Since amphiphilic copolymer covered on CNTs might also effect the signal of $I_{D}$ and $I_{G}$ bands, the meaning of the ratio for PGA MWCNTs might not exactly be defects of CNTs. In this case, PGA bound directly to the Hep and not the MWCNTs; therefore, the PGA did not further damage the MWCNTs.
Moreover, the signals of the polymer chains were difficult to detect because the polymer layer was not continuous; all the characteristic absorption peaks were strongly attenuated after the polymer was tethered to the MWCNT surface. ${ }^{23,24}$

\section{Dynamic light-scattering results}

Dynamic light-scattering measurements provide information on the hydrodynamic diameter ( $Z$-average) of CNTs, which is related to the diameter of the spherical particle and the zeta potential of the material. ${ }^{25}$ The hydrodynamic diameters for $\mathrm{COOH}$, Hep, and PGA MWCNTs are shown in Figure 4A-C. The $Z$-average decreases in the following order: PGA $(258.7 \mathrm{~nm})>\mathrm{COOH}(137.1 \mathrm{~nm})>\operatorname{Hep}(112.0 \mathrm{~nm})$ MWCNTs. Hep MWCNTs had the smallest hydrodynamic diameter, because Hep is hydrophilic, which prevented the aggregation of CNTs. By contrast, Hep MWCNTs, which contained aggregates of various sizes, had the highest PDI of the three CNTs. The PDI of COOH MWCNTs $(0.005)$ was $<0.1$, whereas the PDI of PGA MWCNTs (0.133) was close to 0.1; therefore, they were considered to be monodispersed systems. However, Hep MWCNTs were polydispersed because its PDI, which was 0.267 , was much greater than 0.1 .

\section{Encapsulation of hydrophobic molecules (pyrene)}

An increased drug-loading capacity is important in order for drug carriers to be utilized in pharmaceutical applications.

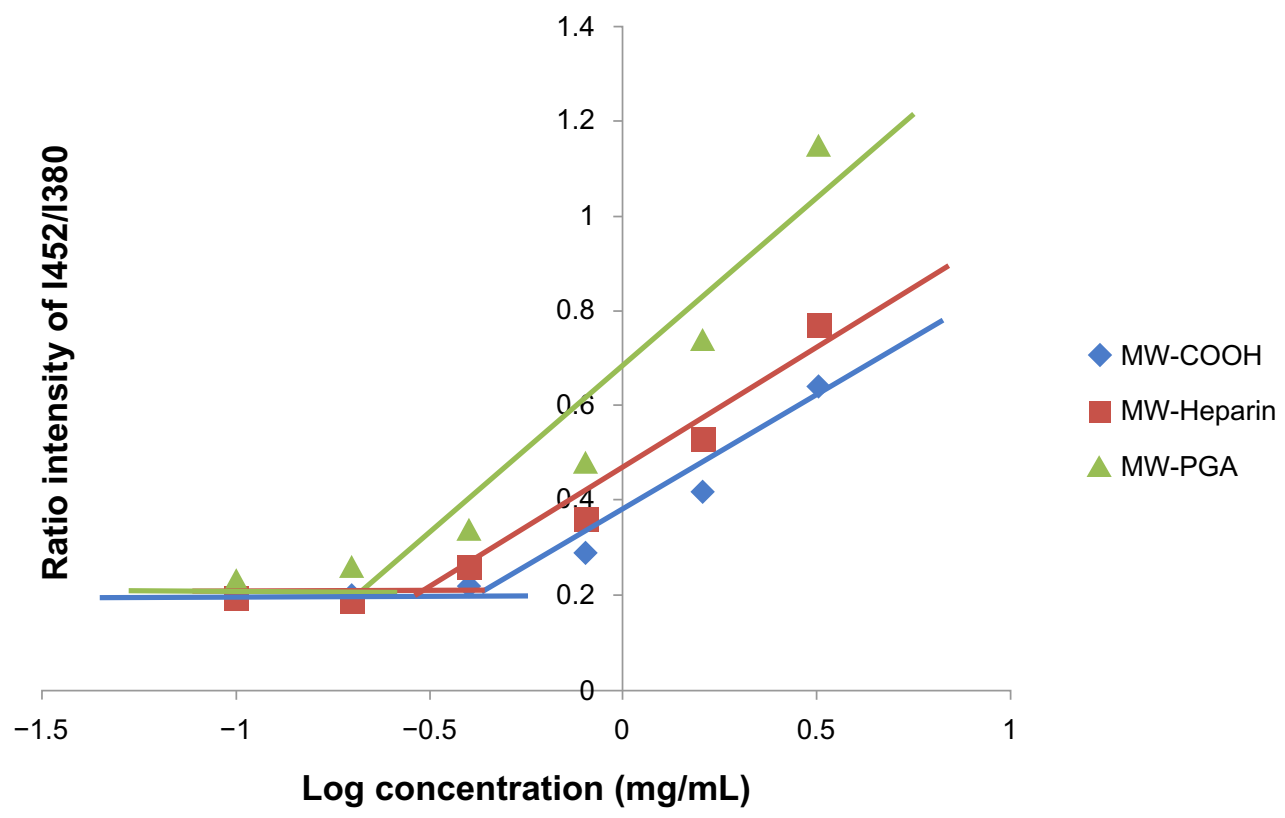

Figure 5 Plot of the fluorescence-intensity ratio of excimer/monomer as a function of multiwalled (MW) oxidized (COOH), MW heparin, and MW polyglycolic acid (PGA) carbon nanotube concentration.

Note: 1452/1380; the ration of fluorescence intensity of pyrene at $452 \mathrm{~nm}$ to $380 \mathrm{~nm}$. 
Table I Doxorubicin (Dox)-loading capacity of multiwalled oxidized $(\mathrm{COOH})$, multiwalled heparin, and multiwalled polyglycolic acid (PGA) carbon nanotubes with a fixed weight of $0.162 \mathrm{mg}$

\begin{tabular}{llll}
\hline Sample & $\begin{array}{l}\text { Weight } \\
\text { of Dox }\end{array}$ & $\begin{array}{l}\text { Weight } \\
\text { of sample }\end{array}$ & $\begin{array}{l}\text { Drug-loading } \\
\text { capacity }\end{array}$ \\
\hline COOH & $0.092 \mathrm{mg}$ & $0.162 \mathrm{mg}$ & 0.573 \\
Heparin & $0.071 \mathrm{mg}$ & $0.162 \mathrm{mg}$ & 0.438 \\
PGA & $0.246 \mathrm{mg}$ & $0.162 \mathrm{mg}$ & 1.519 \\
\hline
\end{tabular}

Therefore, the ability of the three types of CNT carriers to encapsulate hydrophobic molecules was evaluated using pyrene. In the presence of a hydrophobic region or micelles in aqueous media, pyrene preferentially solubilized within the interior of hydrophobic regions. This change in the microenvironment of the probes was reflected by variations in emission and excitation spectra. Therefore, the ratio of fluorescence intensity of the excimer (Ie) to the monomer ( $\mathrm{Im})$ was used to indicate the association between hydrophobic labels. ${ }^{26}$ Figure 5 presents the ratios of fluorescence intensity, with the Ie at $452 \mathrm{~nm}$ and the Im at $380 \mathrm{~nm}$, for samples with varying concentrations; Ie/Im significantly increased with increasing sample concentration. The $\mathrm{COOH}, \mathrm{Hep}$, and PGA MWCNT samples presented different degrees of self-association. The lowest critical association concentration was found for the PGA MWCNT solution, and was attributed to the highly efficient encapsulation of hydrophobic molecules. It has previously been shown that the ratio of the pyrene emission spectrum increases when pyrene molecules are located in more hydrophobic areas. ${ }^{27}$

\section{Drug-loading and zeta-potential results}

The Dox-loading efficiency of samples was determined as described below:

$$
\begin{aligned}
& \text { Dox-loading capacity } \\
& =\frac{\text { Weight of Dox }}{\text { Weight sample (based on MWCNTs) }}
\end{aligned}
$$

Table 1 shows that PGA MWCNTs had the highest drug-loading efficiency. Because of hydrophobic interactions between PGA and the drug, PGA MWCNTs were significantly more efficient at encapsulating drugs than $\mathrm{COOH}$ or Hep MWCNTs. Moreover, additional space on the PGA MWCNTs allowed the attachment of drugs to the MWCNT side walls via hydrophobic interactions and $\pi-\pi$ stacking. In general, polymeric micelle-based carriers can achieve substantial drug-loading levels of approximately $15 \%-20 \%{ }^{28}$ In the PGA MWCNT system, drug-loading levels were threefold higher than the $\mathrm{COOH}$ MWCNT system and tenfold higher than reported polymeric micelle systems. By contrast, Hep MWCNTs had the lowest drug-loading

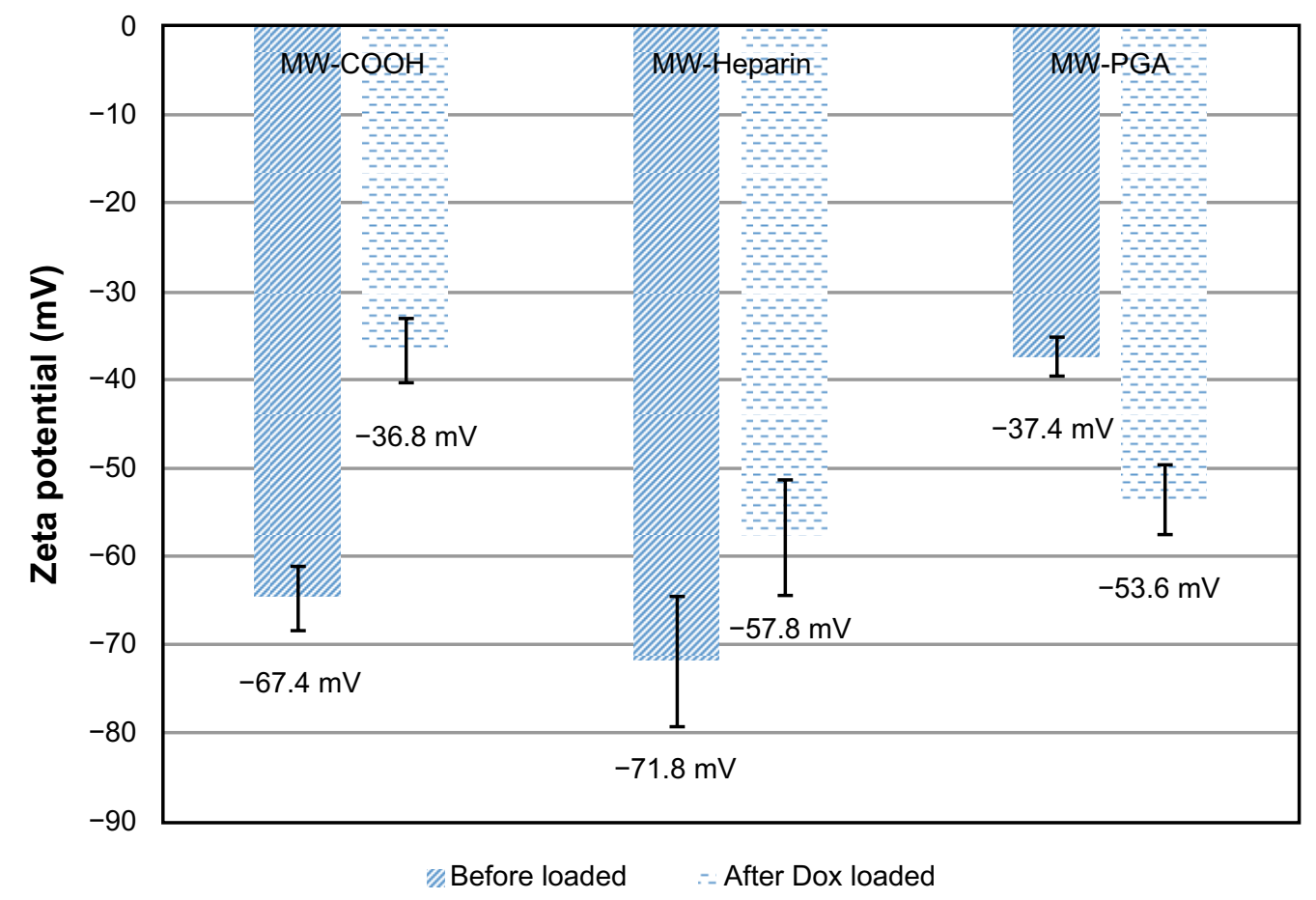

Figure 6 Zeta potentials of multiwalled (MW) oxidized (COOH), MW heparin (Hep), MW polyglycolic acid (PGA), doxorubicin (Dox)-loaded MW COOH, Dox-loaded MW Hep, and Dox-loaded MW PGA carbon nanotubes. 

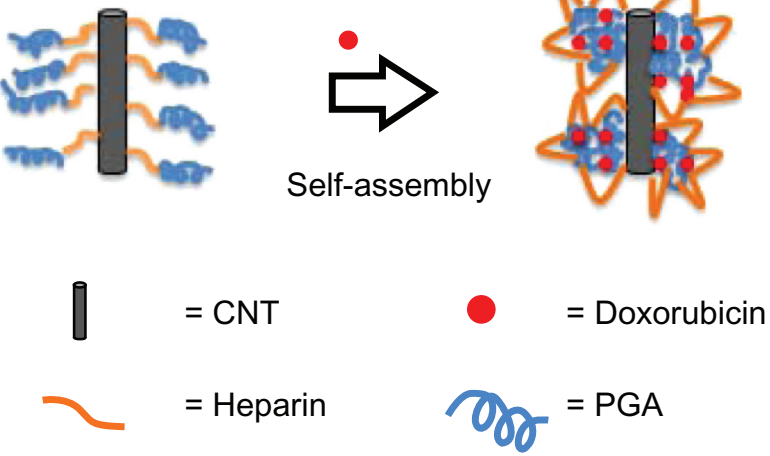

Figure 7 Drug-loading mechanism for the multiwalled polyglycolic acid (PGA) carbon nanotube (CNT) system and doxorubicin.

efficiency. This is because Hep MWCNTs are bulkier, which might have inhibited the attachment of Dox.

The zeta potentials of the $\mathrm{COOH}$, Hep and PGA MWCNTs were negative in value, as shown in Figure 6. After acid treatment, negatively charged carboxylic acid groups were incorporated on the tip and outer shell of the CNTs. Therefore, $\mathrm{COOH}$ MWCNTs had a negative zeta potential $(-67.4 \mathrm{mV})$. By contrast, Hep and PGA MWCNTs, which have negatively charged surfaces, had zeta potentials of -71.8 and $-37.4 \mathrm{mV}$, respectively. Charged polymers that are attached to CNTs have a tendency to retain their charge so that the zeta potentials reflect the charge of the polymer on the CNT surface. ${ }^{29}$ Therefore, the addition of negatively charged Hep to the CNTs yielded a zeta potential with a high negative charge. The addition of PGA to the Hep MWCNT surface reduced the zeta potential.

Drug loading of each sample resulted in zeta potentials that were different from blank samples. When drug was loaded onto $\mathrm{COOH}$ and Hep MWCNTs, the zeta potential changed from $-67.4 \mathrm{mV}$ (COOH MWCNTs) to $-36.8 \mathrm{mV}$ (COOH-Dox MWCNTs) and from $-71.8 \mathrm{mV}$ (Hep MWCNTs) to $-57.8 \mathrm{mV}$ (Hep-Dox MWCNTs), respectively. This occurred because positively charged Dox was loaded onto $\mathrm{COOH}$ and Hep MWCNTs through electrostatic interactions and $\pi-\pi$ stacking, which reduced the negative charge. However, when the drug was loaded onto PGA MWCNTs, the zeta potential shifted to a more negative potential (ie, from $-37.4 \mathrm{mV}$ [PGA MWCNTs] to $-53.6 \mathrm{mV}$ [PGA-Dox MWCNTs]). In this case, Dox was loaded onto PGA MWCNTs via hydrophobic interactions and stacking. The PGA and Dox self-assembled and attached to the side walls of the MWCNTs, and the Hep bound to the exterior of the MWCNTs. This could be the reason a different trend in the zeta potential was observed for the Dox-loaded PGA MWCNT carrier system. The self-assembly mechanism of Dox and PGA is shown in Figure 7.

\section{Biocompatibility test}

To determine the viability of cells in culture, the MTT assay was used. Figure 8 shows the viability of cells cultured with

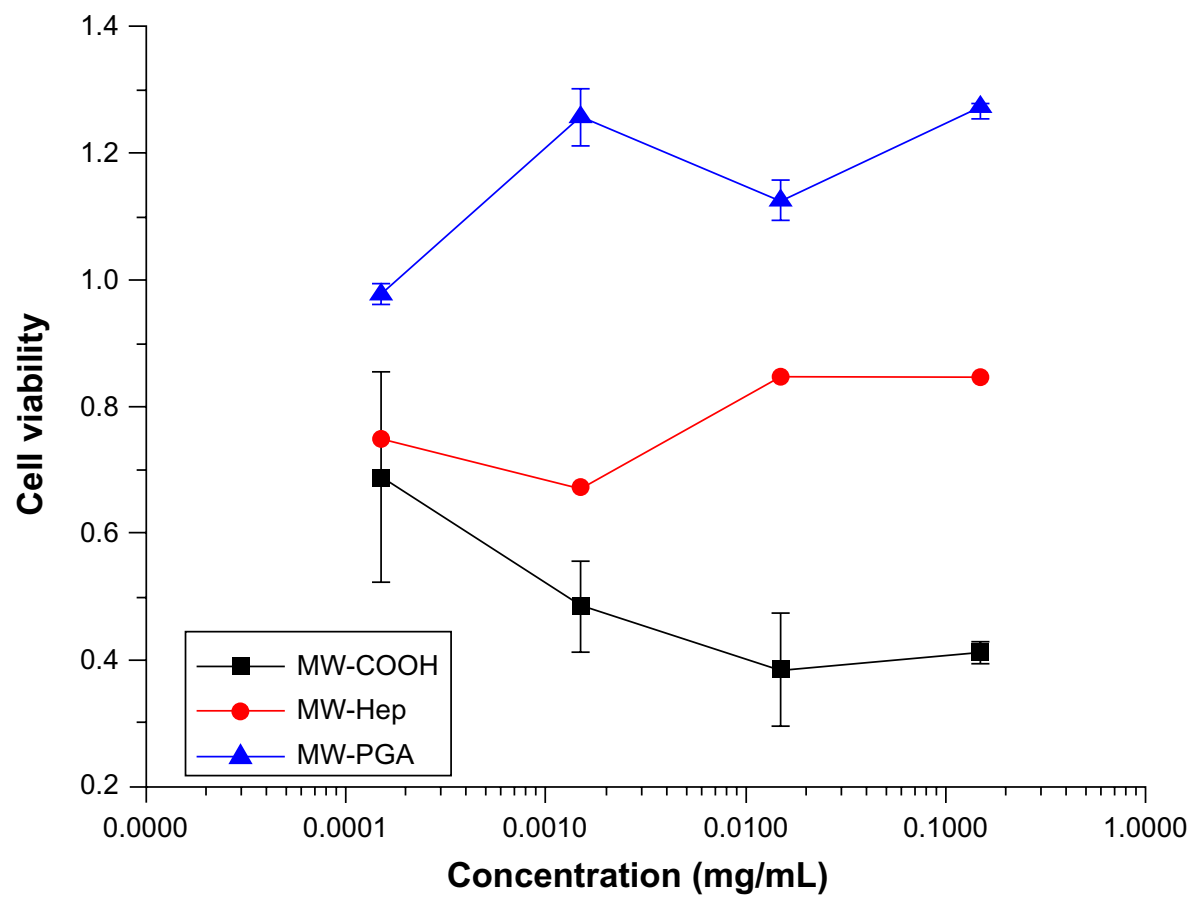

Figure 8 Cytotoxicity of multiwalled (MW) oxidized (COOH), MW heparin (Hep), MW polyglycolic acid (PGA) carbon nanotubes after incubation with HeLa cells for 24 hours at $37^{\circ} \mathrm{C}$. 
$\mathrm{COOH}$, Hep, and PGA MWCNTs. These results show that $\mathrm{COOH}$ MWCNTs had the highest toxicity compared to Hep and PGA MWCNTs. Although the toxicity of CNTs has not been thoroughly studied, some parameters, such as size distribution, surface area, charge, surface chemistry, and impurity, have been shown to significantly affect CNT reactivity. It has been reported that CNTs can penetrate human cells, accumulate in the cytoplasm, and cause cell death under certain conditions. ${ }^{30}$

One report confirmed that Hep could be safely utilized as a drug carrier without the risk of inducing hemorrhages or other side effects. ${ }^{31}$ Wheeler et $\mathrm{al}^{32}$ reported that Hep was not significantly cytotoxic to cells, which might be the reason Hep MWCNTs were slightly less toxic than $\mathrm{COOH}$ MWCNTs. In addition, PGA MWCNTs had the lowest toxicity and highest cell viability. This is attributed to the modification of PGA with Hep, which weakened the initial negative surface charge, and the complete surface coverage of the MWCNTs with hydrophobic PGA.

Our study also confirmed that the material surface plays an important role in determining toxicity. For example, the addition of neutral PGA reduced the negative charge of PGA MWCNTs compared to Hep and COOH MWCNTs. Therefore, PGA MWCNTs are more biocompatible, as verified by cell-viability experiments. Results from the drug-loading capacity experiment indicate that PGA MWCNTs encapsulated Dox better than the $\mathrm{COOH}$ and Hep MWCNT systems. Therefore, PGA MWCNTs were chosen as the drug.

\section{Cellular uptake of Dox-loaded PGA MWCNTs}

Cellular uptake and intracellular drug-release studies on free Dox and Dox-PGA MWCNTs were observed using confocal microscopy. To identify the carrier and drug in the cells, PGA MWCNTs were conjugated with FITC. The fluorescence spectrum of FITC-PGA MWCNTs is shown in Figure S2. Figure 9A shows the distribution of Dox (red fluorescence) in the nuclei of HeLa cells after incubation for either 30 minutes or 2 hours. Longer incubation times resulted in stronger fluorescence signals in HeLa cell nuclei, which indicates higher drug penetration. A strong green fluorescence signal, attributed to FITC-PGA MWCNTs, was observed in the nucleoli, whereas a relatively weaker signal was observed in the cytoplasm (Figure 9B). HeLa cells that were incubated for 2 hours with PGA-Dox MWCNTs exhibited clear dots in the nucleus. These dots are caused by the nuclear accumulation of FITC-PGA MWCNTs.
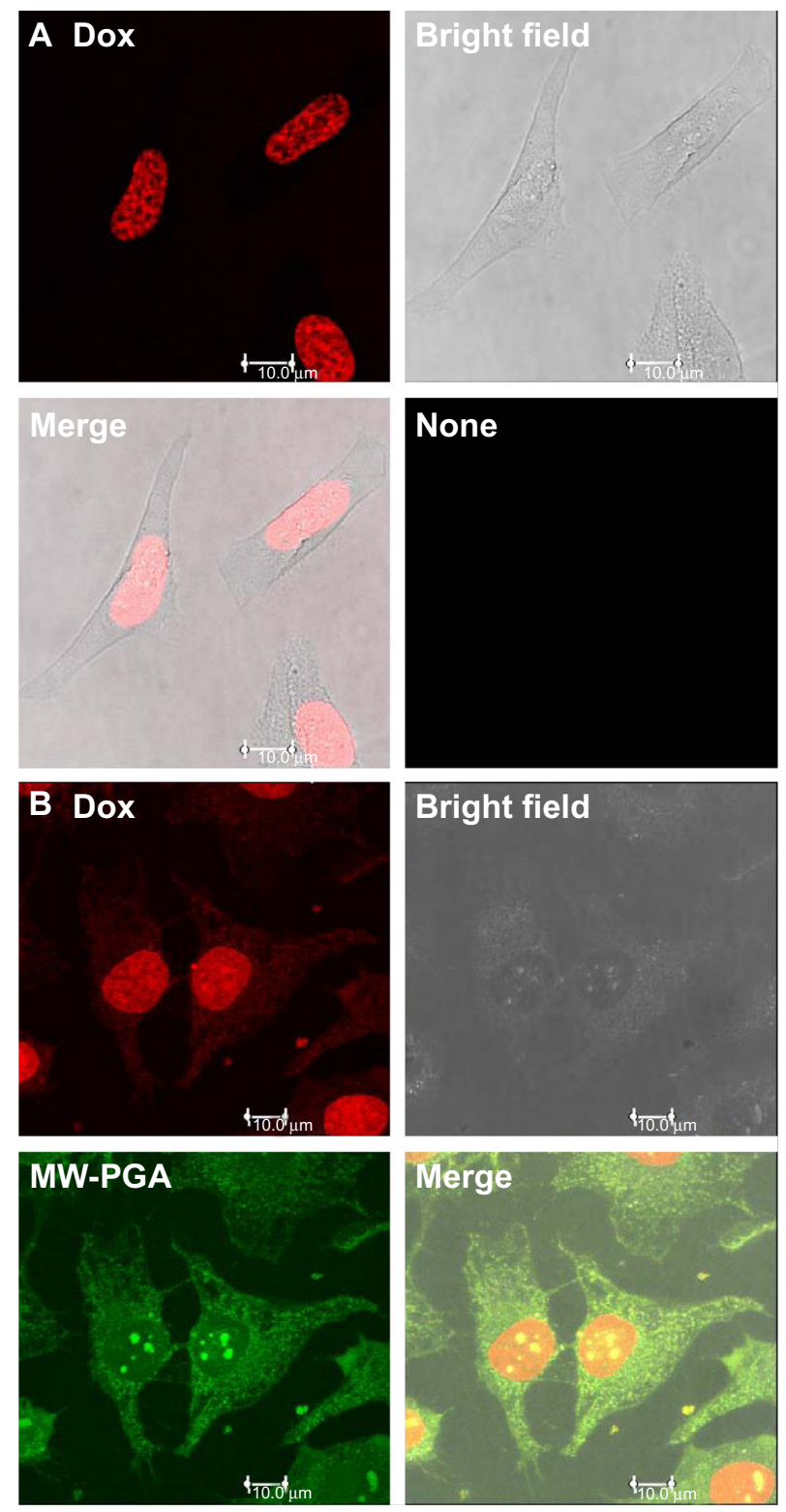

Figure 9 Confocal microscopy images of (A) free doxorubicin (Dox) and (B) multiwalled (MW) polyglycolic acid (PGA)-Dox carbon nanotubes incubated with HeLa cells for 2 hours. Red fluorescence means Dox and green fluorescence means PGA.

However, the nuclear-targeting mechanism of CNTs has not been identified. Other studies have demonstrated that the cellular uptake of NTs is significantly affected by NT length. NTs that are shorter than $1 \mu \mathrm{m}$ are more easily internalized via energy-independent pathways. ${ }^{33}$ SEM and TEM measurements showed that the average diameter and length of the PGA MWCNTs used in our study were $37.1 \mathrm{~nm}$ and $189.0 \mathrm{~nm}$, respectively. Therefore, it was possible for PGA MWCNTs to be translocated to the nucleus (as shown in the confocal image), and the process of PGA MWCNT accumulation may involve certain internalization processes and interactions with nuclear proteins and nucleic acids. ${ }^{34}$ 
Red fluorescence (caused by Dox and Dox-PGA MWCNTs) was detected in the nucleus. The Hep molecules of PGA MWCNTs interacted with nuclear proteins, which may have induced the release of Dox from PGA MWCNTs. Although we cannot simulate the surrounding nucleus, we hope that Dox-loaded PGA MWCNTs are stable in lysosomal or cytoplasmic environments. The simulated release profile is shown in Figure S3. Dox release was extremely low in extracellular (10 mM PBS, pH 7.4), lysosomal (pH 4.5), and reductive (10 mM PBS + $3 \mathrm{mM}$ dithiothreitol) environments. After 24 hours, the drug release was determined to be approximately $20 \%$ for all simulated environments. The results shown in the confocal image indicate that PGA MWCNTs can transport and release Dox in the nucleus of HeLa cells.

\section{In vitro cell toxicity of PGA-Dox MWCNTs}

In order to evaluate the delivery of DNA toxins from the PGA MWCNT carrier, we compared the cytotoxicity of PGA-Dox MWCNTs to free Dox in HeLa cells. In Figure 10, HeLa cell viability decreased with increasing Dox concentrations of free Dox and PGA-Dox MWCNTs. Our results confirmed that free Dox was less cytotoxic than PGA-Dox MWCNTs at equivalent Dox dosages. Blank PGA MWCNTs did not show any toxicity, which indicates that the cytotoxicity of PGA-Dox MWCNTs is attributed to the delivery mechanism. These results demonstrate that the toxicity of PGA-Dox MWCNTs is attributed to drug that is released from the PGA MWCNT carrier into the nucleus. Free Dox was transferred into cells via passive diffusion, which is less effective than delivery from Dox-loaded carriers (PGA MWCNTs).

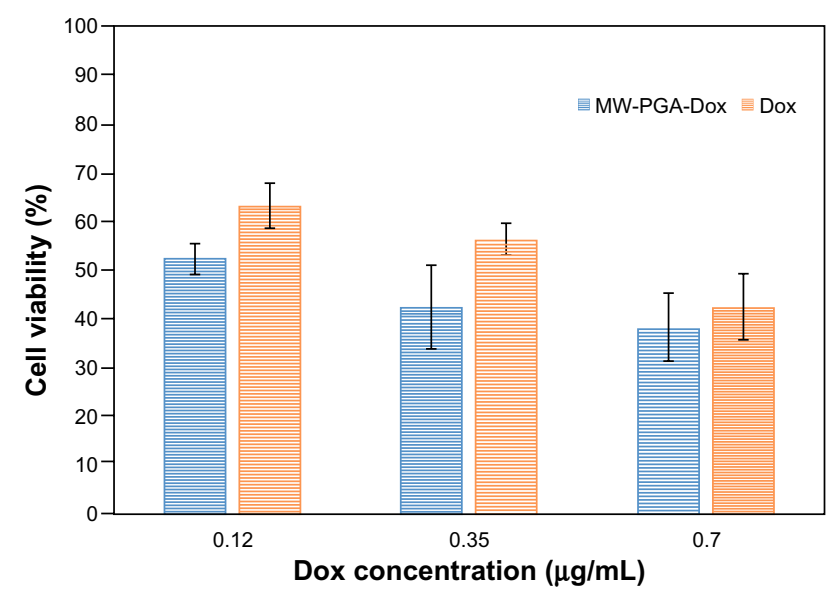

Figure 10 The cytotoxicity of free doxorubicin (Dox) and Dox-loaded multiwalled (MW) polyglycolic acid (PGA) carbon nanotubes after incubation with HeLa cells for 24 hours at $37^{\circ} \mathrm{C}$.

\section{Conclusion}

A highly effective drug-delivery system based on functionalized MWCNTs has been developed that overcomes the limitation of other CNT-based systems. To improve the drug-loading capacity of CNTs, an amphiphilic copolymer was conjugated to MWCNTs. Accordingly, three types of hybrid NTs, ie, $\mathrm{COOH}$, Hep, and PGA MWCNTs, were designed and synthesized as drug carriers in this study. Based on the specific structure of each hybrid NT, the drug was encapsulated by the hybrid NTs through different mechanisms. Dox, which is a cancer drug, adhered to $\mathrm{COOH}$ and Hep MWCNTs through $\pi-\pi$ stacking and electrostatic interactions. In the PGA MWCNT system, the amphiphilic copolymer formed micelles on the side walls of the MWCNTs and presented loop-shaped micelles, as confirmed by electron microscopy. Therefore, Dox was encapsulated not only by $\pi-\pi$ stacking interactions but also through hydrophobic interactions between PGA and the MWCNTs. In addition, the advantage of nuclear-targeted drug delivery is to escort DNA toxins directly to the targeted site and overcome intracellular drug resistance. Thus, the development of nuclear-targeting drug carriers is important for the advancement of clinical chemotherapy treatments with high therapeutic efficacy. The PGA MWCNT carrier demonstrated high drug-carrier and nuclear-targeting abilities. In cell experiments, we found that Dox was efficiently released from PGA MWCNTs into the nucleus and induced cell death. Together, we may eventually achieve successful nuclear-targeted delivery of chemotherapy drugs with the PGA MWCNT carrier that will improve cancer treatments. In summary, this study demonstrates the considerable potential of amphiphilic copolymer-conjugated NTs as carriers for drug-delivery systems.

\section{Acknowledgments}

The authors would like to thank the National Science Council of the Republic of China (Taiwan) and National Taiwan University of Science and Technology - Taipei Medical University Joint Research Program for financially supporting this work (NSC 100-2221-E-007-011-030-MY3, 100-2511-S-011-006-MY2, and NTUST-TMU-No 100-12). TTY Biopharm Co, Ltd (Taiwan) is appreciated for kindly providing the doxorubicin hydrochloride.

\section{Disclosure}

The authors report no conflicts of interest in this work.

\section{References}

1. Jong WHD, Borm PJ. Drug delivery and nanoparticles: applications and hazards. Int J Nanomedicine. 2008;3:133-149. 
2. Yang Z, Zhang Y, Yang Y, et al. Pharmacological and toxicological target organelles and safe use of single-walled carbon nanotubes as drug carriers in treating Alzheimer disease. Nanomedicine. 2010;6:427-441.

3. Hwang JY, Shin US, Jang WC, Hyun JK, Wall IB, Kim HW. Biofunctionalized carbon nanotubes in neural regeneration: a minireview. Nanoscale. 2013;5:487-497.

4. Mu Q, Broughton DL, Yan B. Endosomal leakage and nuclear translocation of multiwalled carbon nanotubes: developing a model for cell uptake. Nano Lett. 2009;9:4370-4375.

5. Zhang W, Zhang Z, Zhang Y. The application of carbon nanotubes in target drug delivery systems for cancer therapies. Nanoscale Res Lett. 2011;6:555.

6. Wang H, Michielssens S, Moors SLC, Ceulemans A. Molecular dynamics study of dipalmitoylphosphatidylcholine lipid layer self-assembly onto a single-walled carbon nanotube. Nano Res. 2009;2:945-954.

7. Liu Z, Tabakman S, Welsher K, Dai H. Carbon nanotubes in biology and medicine: in vitro and in vivo detection, imaging and drug delivery. Nano Res. 2009;2:85-120.

8. Ali-Boucetta H, Al-Jamal KT, McCarthy D, Prato M, Bianco A, Kostarelos K. Multiwalled carbon nanotube-doxorubicin supramolecular complexes for cancer therapeutics. Chem Commun (Camb). 2008:459-461.

9. Gu YJ, Cheng J, Jin J, Cheng SH, Wong WT. Development and evaluation of $\mathrm{pH}$-responsive single-walled carbon nanotube-doxorubicin complexes in cancer cells. Int J Nanomedicine. 2011;6:2889-2898.

10. Zhang R, Olin H. Carbon nanomaterials as drug carriers: real time drug release investigation. Mater Sci Eng C Mater Biol Appl. 2012;32: 1247-1252.

11. Gorantla S, Avdoshenko S, Börrnert F, et al. Enhanced $\pi-\pi$ interactions between a $\mathrm{C} 60$ fullerene and a buckle bend on a double-walled carbon nanotube. Nano Res. 2010;3:92-97.

12. Wall ME, Wani MC. Camptothecin and taxol: from discovery to clinic. J Ethnopharmacol. 1996;51:239-254

13. Mizutani H, Oikawa S, Hiraku Y, Murata M, Kojima M, Kawanishi S. Distinct mechanisms of site-specific oxidative DNA damage by doxorubicin in the presence of copper(II) and NADPH-cytochrome P450 reductase. Cancer Sci. 2003;94:686-691.

14. Zhou Z, Shen Y, Tang J, et al. Charge-reversal drug conjugate for targeted cancer cell nuclear drug delivery. Adv Func Mater. 2009;19: 3580-3589.

15. Sui M, Liu W, Shen Y. Nuclear drug delivery for cancer chemotherapy. J Control Release. 2011;155:227-236.

16. Pantarotto D, Briand JP, Prato M, Bianco A. Translocation of bioactive peptides across cell membranes by carbon nanotubes. Chem Commun (Camb). 2004;1:16-17.

17. Pantarotto D, Singh R, McCarthy D, et al. Functionalized carbon nanotubes for plasmid DNA gene delivery. Angew Chem Int Ed Engl. 2004; 43:5242-5246.

18. Haniu H, Saito N, Matsuda Y, et al. Effect of dispersants of multiwalled carbon nanotubes on cellular uptake and biological response. Int J Nanomedicine. 2011;6:3295-3307.

19. Nakashima A, Mori K, Sasaki S. Interaction between polyanions and cell nuclei: mechanism of gelatination of nuclei. Biochem Biophys Res Commun. 1996;228:846-851.
20. Anderson NG, Wilbur KM. Studies on isolated cell components II. The release of a nuclear gel by heparin. J Gen Physiol. 1951;34:647-656.

21. Yan LY, Li W, Fan XF, et al. Enrichment of $(8,4)$ single-walled carbon nanotubes through coextraction with heparin. Small. 2010;6: 110-118.

22. Everaerts F, Torrianni M, Hendriks M, Feijen J. Biomechanical properties of carbodiimide crosslinked collagen: influence of formation of ester crosslinks. J Biomed Mater Res A. 2007;85:547-555.

23. Gao C, Jin YZ, Kong H, et al. Polyurea-functionalized multiwalled carbon nanotubes: synthesis, morphology, and raman spectroscopy. J Phys Chem B. 2005;109:11925-11932.

24. Mashat A, Deng L, Altawashi A, Sougrat R, Wang GC, Khashab NM. Zippered release from polymer-gated carbon nanotubes. J Mater Chem. 2012;22:11503-11508.

25. Wang Y, Kim JH, Baek JB, Miller GW, Pennell KD. Transport behavior of functionalized multi-wall carbon nanotubes in watersaturated quartz sand as a function of tube length. Water Res. 2012;46: 4521-4531.

26. Li M, Jiang M, Zhang YX, Fang Q. Fluorescence studies of hydrophobic association of fluorocarbon-modified poly(N-isopropylacrylamide). Macromolecules. 1997;30:470-478.

27. Herkstroeter WG, Martic PA, Hartman SE, Williams JLR, Farid. Unique hydrophobic interaction of pyrene in aqueous solution as effected by polyelectrolytes and surfactants. J Polym Sci A Polym Chem. 1983;21:2473-2490.

28. Sanson C, Schatz C, Le Meins JF, et al. A simple method to achieve high doxorubicin loading in biodegradable polymersomes. J Control Release. 2010;147:428-435.

29. Sun Z, Nicolosi V, Rickard D, Bergin SD, Aherne D, Coleman JN. Quantitative evaluation of surfactant-stabilized single-walled carbon nanotubes dispersion quality and its correlation with zeta potential. J Phys Chem C Nanomater Interfaces. 2008;112:10692-10699.

30. Porter AE, Gass M, Muller K, Skepper JN, Midgley PA, Welland M. Direct imaging of single-walled carbon nanotubes in cells. Nat Nanotechnol. 2007;2:713-717.

31. Cho KJ, Moon HT, Park GE, Jeon OC, Byun Y, Lee YK. Preparation of sodium deoxycholate (DOC) conjugated heparin derivatives for inhibition of angiogenesis and cancer cell growth. Bioconjug Chem. 2008;19:1346-1351.

32. Wheeler RH, Bull FE, Ruddon RW. The effect of heparin on the cytotoxicity and uptake of anti-neoplastic drugs in cultured Burkitt lymphoma cells. Cancer Res. 1974;34:3215-3219.

33. Raffa V, Ciofani G, Nitodas S, et al. Can the properties of carbon nanotubes influence their internalization by living cells? Carbon $N Y$. 2008;46:1600-1610.

34. Cheng J, Fernando KS, Veca LM, et al. Reversible accumulation of PEGylated single-walled carbon nanotubes in the mammalian nucleus. ACS Nano. 2008;2:2085-2094. 


\section{Supplementary materials}
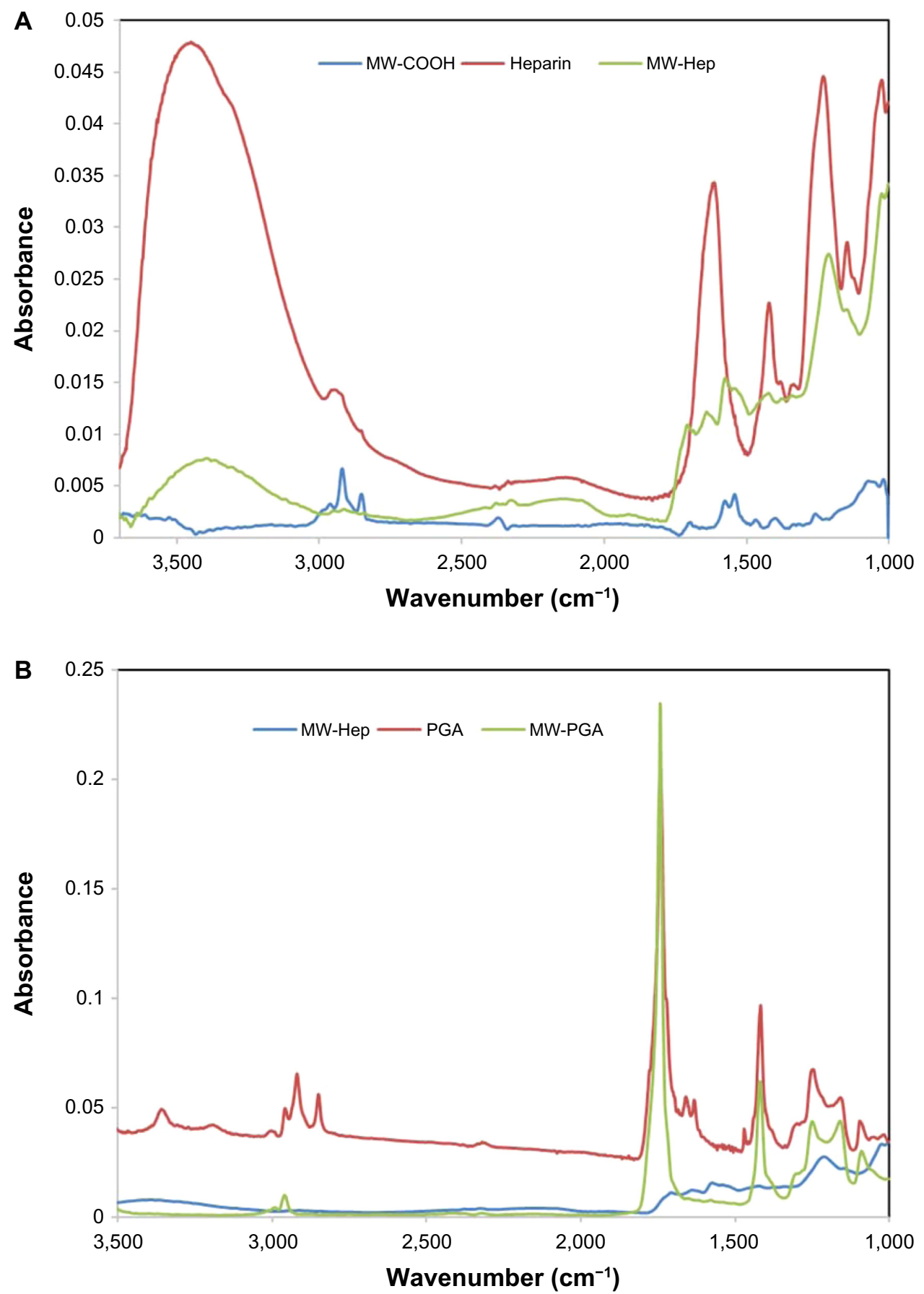

Figure SI FTIR analysis of (A) multiwalled (MW) oxidized (COOH), heparin (Hep), MW Hep and (B) MW Hep, polyglycolic acid (PGA), and MW PGA carbon nanotubes.

Abbreviations: FTIR, Fourier-transform infrared. 


\section{Fluorescence emission spectra \\ excited at $488 \mathrm{~nm}$}

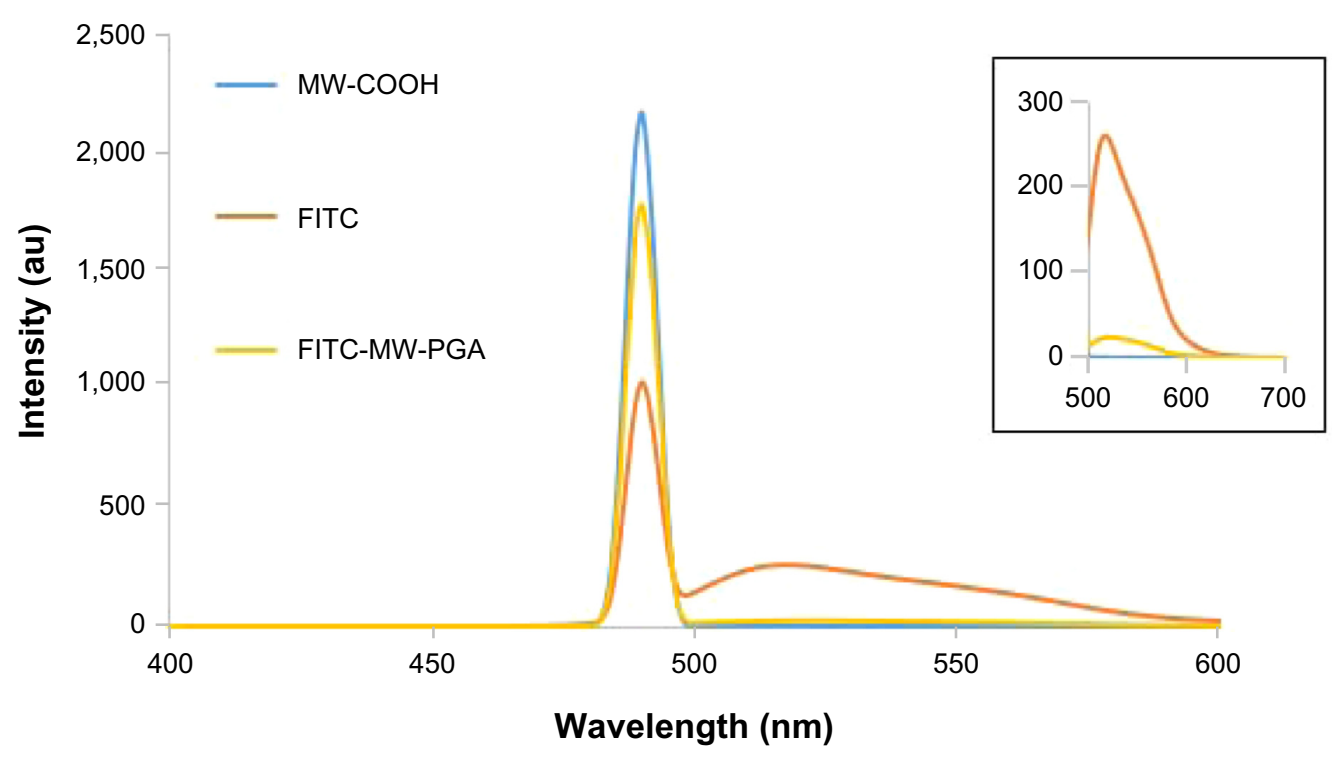

Figure S2 Fluorescence spectra of multiwalled $(\mathrm{MW})$ oxidized $(\mathrm{COOH})$ carbon nanotubes, FITC, and FITC-MW-PGA solution. Abbreviations: FITC, fluorescein isothiocyanate; PGA, polyglycolic acid.

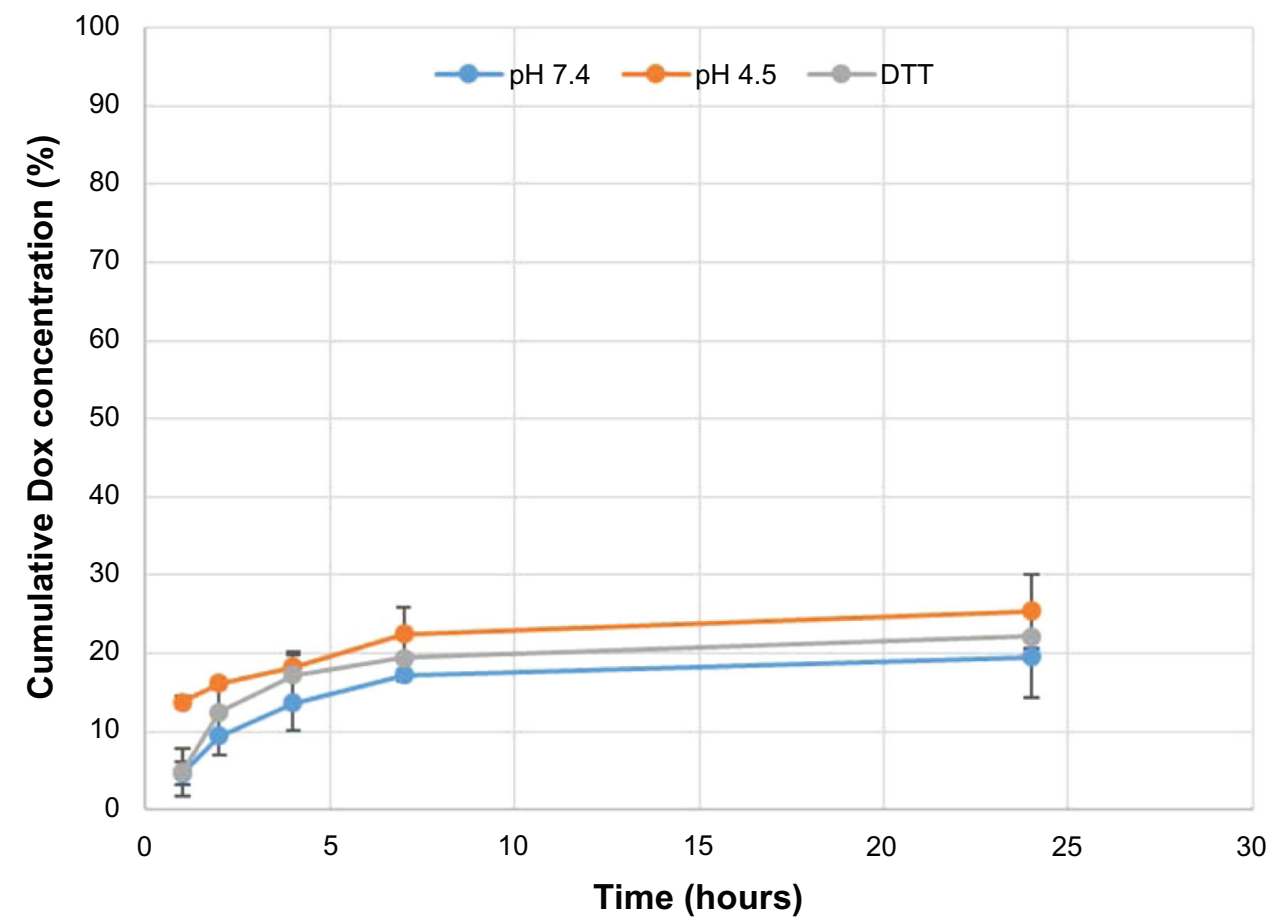

Figure S3 Release rate of doxorubicin (Dox) from diblock copolymer polyglycolic acid-co-heparin conjugated to multiwalled carbon nanotubes at 10 mM phosphate buffer solution, $\mathrm{pH} 7.4, \mathrm{pH} 4.5$, and $3 \mathrm{mM}$ dithiothreitol (DTT).

International Journal of Nanomedicine

Dovepress

\section{Publish your work in this journal}

The International Journal of Nanomedicine is an international, peerreviewed journal focusing on the application of nanotechnology in diagnostics, therapeutics, and drug delivery systems throughout the biomedical field. This journal is indexed on PubMed Central, MedLine, CAS, SciSearch ${ }^{\circledR}$, Current Contents $₫ /$ Clinical Medicine,
Journal Citation Reports/Science Edition, EMBase, Scopus and the Elsevier Bibliographic databases. The manuscript management system is completely online and includes a very quick and fair peer-review system, which is all easy to use. Visit http://www.dovepress.com/ testimonials.php to read real quotes from published authors.

Submit your manuscript here: http://www.dovepress.com/international-journal-of-nanomedicine-journal 